\title{
An. gambiae s.l. exhibit high intensity pyrethroid resistance throughout Southern and Central Mali (2016-2018); PBO or next generation LLINs may provide greater control
}

\author{
Arthur Sovi \\ London School of Hygiene and Tropical Medicine \\ Chitan Keita \\ ABT Associates Inc \\ Youssouf Sinaba \\ ABT Associates Inc \\ Abdourhamane Dicko \\ National Malaria Control Program \\ Ibrahim Traore \\ Universite des Sciences, des Techniques et des Technologies du Bamako (USTTB) \\ Moussa BM Cisse \\ Universite des Sciences, des Techniques et des Technologies du Bamako (USTTB) \\ Ousmane Koita \\ Universite des Sciences, des Techniques et des Technologies du Bamako (USTTB) \\ Dereje Dengela \\ ABT Associates Inc \\ Cecilia Flatley \\ ABT Associates Inc \\ Elie Bankineza \\ ABT Associates Inc \\ Jules Mihigo \\ USAID \\ Allison Belemvire \\ USAID \\ Jenny Carlson \\ USAID \\ Christen Fornadel \\ USAID \\ Richard Martin Oxborough ( $\nabla$ oxandbull@hotmail.com ) \\ PMI VectorLink Project, Abt Associates
}

Research

Keywords: Susceptibility test, Resistance intensity, WHO tube test, CDC bottle bioassay, Piperonyl butoxide, Vector control, Indoor residual spraying, Long-lasting insecticidal net, Anopheles gambiae, Mali

Posted Date: April 21st, 2020

DOI: https://doi.org/10.21203/rs.2.24378/v3 
License: @ (i) This work is licensed under a Creative Commons Attribution 4.0 International License. Read Full License

Version of Record: A version of this preprint was published at Parasites \& Vectors on May 8th, 2020. See the published version at https://doi.org/10.1186/s13071-020-04100-7. 


\section{Abstract}

Background: Millions of pyrethroid LLINs have been distributed in Mali during the past 20 years which, along with agricultural use, has increased the selection pressure on malaria vector populations. This study investigated pyrethroid resistance intensity and susceptible status of malaria vectors to alternative insecticides to guide choice of insecticides for LLINs and IRS for effective control of malaria vectors.

Methods: For 3 years between 2016 and 2018, susceptibility testing was conducted annually in 14-16 sites covering southern and central Mali. Anopheles gambiae s.I. were collected from larval sites and adult mosquitoes exposed in WHO tube tests to diagnostic doses of bendiocarb (0.1\%) and pirimiphos-methyl (0.25\%). Resistance intensity tests were conducted using CDC bottle bioassays (2016-17) and WHO tube tests (2018) at $1 \times, 2 \times, 5 \times$, and $10 \times$ the diagnostic concentration of permethrin, deltamethrin and alpha-cypermethrin. WHO tube tests were conducted with pre-exposure to the synergist PBO followed by permethrin or deltamethrin. Chlorfenapyr was tested in CDC bottle bioassays at $100 \mu \mathrm{g}$ active ingredient per bottle and clothianidin at $2 \%$ in WHO tube tests. PCR was performed to identify species within the An. gambiae complex.

Results: In all sites An. gambiae s.I. showed high intensity resistance to permethrin and deltamethrin in CDC bottle bioassay tests in 2016 and 2017. In 2018, WHO intensity tests resulted in survivors at all sites for permethrin, deltamethrin and alphacypermethrin when tested at $10 \times$ the diagnostic dose. Across all sites mean mortality was $33.7 \%$ with permethrin $(0.75 \%)$ compared with $71.8 \%$ when pre-exposed to PBO (4\%), representing a 2.13 fold increase in mortality. A similar trend was recorded for deltamethrin. There was susceptibility to pirimiphos-methyl, chlorfenapyr and clothianidin in all surveyed sites, including current IRS sites in Mopti Region. An. coluzzii was the primary species in 4 of 6 regions.

Conclusions: Widespread high intensity pyrethroid resistance was recorded during 2016-18 and is likely to compromise the effectiveness of pyrethroid LLINs in Mali. PBO or chlrofenapyr LLINs should provide improved control of An. gambiae s.l. Clothianidin and pirimiphos-methyl insecticides are currently being used for IRS as part of a rotation strategy based on susceptibility being confirmed in this study.

\section{Background}

Malaria remains an important disease in Mali, with the Demographic and HealthSurvey (DHS) of 2018 estimating the prevalence in children aged 6-59 months to be highest in the regions of Sikasso (30\%), Segou (26\%), Mopti (25\%) and Koulikoro (22\%); with Bamako having the lowest prevalence (1\%) [1]. The Mali National Malaria Control Program (NMCP) relies on two methods of malaria vector control; namely nationwide distribution of long-lasting insecticidal nets (LLINs) and targeted indoor residual spraying (IRS). Since 2004, efforts have been made by the Mali NMCP, supported by donors including the U.S. President's Malaria Initiative (PMI) and The Global Fund, to reach universal coverage of LLINs (1 net for every 2 people) throughout the country[2]. Millions of pyrethroid LLINs have been distributed in Mali during the past 20 years which, along with agricultural use of pyrethroids, has increased the selection pressure on malaria vector populations. Mass LLIN distribution campaigns are conducted on a staggered basis at the regional level approximately every three years, with recent mass campaigns that took place in Kayes and Mopti regions in 2017 and Koulikoro and Sikasso regions in 2018. In addition, since 2006 the NMCP has supported free distribution of LLINs to pregnant women during antenatal care and children following vaccination [2]. In 2018 the average number of LLINs owned per household was relatively high in Southern and Central Mali, with an average of 2.2 (Bamako) to 3.0 (Mopti) LLINs per household. Questionnaires as part of the Demographic Health Survey in 2018 showed that $56 \%$ of the population in Bamako slept under an LLIN the previous night, while the highest rate was in Mopti Region at $82 \%$ [1].

PMI Indoor Residual Spraying (IRS) was conducted annually in selected high malaria burden districts, covering between 100,000 to 250,000 houses, since 2008. A pyrethroid insecticide (lambda-cyhalothrin) was used for IRS for three years from 2008-2011, in Bla and Koulikoro districts, with the addition of Baroueli district in 2011. Following the detection of pyrethroid resistance, a carbamate insecticide (bendiocarb WP), was sprayed for 4 years (2011-2014). Wagman et al.,2018 showed that during 20122014, rapid reductions in malaria incidence were observed during the 6 months following each IRS campaign in Segou Region, with an estimated 286,745 total fewer cases of all-age malaria observed in IRS districts [3]. 
Between 2014 and 2018 a long-lasting organophosphate formulation was sprayed (pirimiphos-methyl CS) annually. According to the Malaria Indicator Survey of 2015, the incidence of malaria in the Mopti region was twice that of the national average [4]. Therefore, IRS operations were relocated to 4 districts (Djenné, Mopti, Bandiagara and Bankass) of Mopti Region where an organophosphate in 2017, and an organophosphate and neonicotinoid were sprayed in 2018.

While the efficacy of LLINs [5] and IRS [6] in reducing malaria transmission is proven beyond doubt, insecticide resistance seriously threatens to jeopardize vector control efforts [7, 8]. A previous study by Cissé et al. in 2012 showed widespread pyrethroid resistance in Anopheles gambiae s.l., the main malaria vector complex in Mali [9]. It is therefore important to regularly monitor the susceptibility level of malaria vectors to insecticides used for vector control to help guide national decision making. This study was performed in Mali for 3 years between 2016 and 2018 in 16 sites nationwide, with the primary aim being to update information on the susceptibility status of An. gambiae s.I. to pyrethroid, carbamate, organophosphate, neonicotinoid and pyrolle insecticides that can be used for malaria control. Additionally, the intensity of resistance to pyrethoids that are used on LLINs and the response to the synergist piperonyl butoxide (PBO) was determined.

\section{Methods}

\section{Study area}

The study was conducted in 2016 and 2017 in 16 monitoring sites located within 6 regions covering Southern and Central Mali. In 2018, tests were conducted in 14 sites, with no testing conducted in Fana and Baroueli. No testing was conducted in Northern Mali (Gao, Kidal and Timbuktu regions) due to security concerns. These 16 sites were selected for various reasons, including selection pressure from agriculture and public health vector control (Table 1) and previous use by NMCP for resistance monitoring. By using the same sites annually, resistance trends to insecticides in mosquitoes could be monitored over time. Geographical locations of the 16 sites are shown in Figure 1.

\section{Mosquito larvae collections and rearing}

Larval collections of An. gambiae s.I. were conducted annually in the monitoring sites in 2016, 2017 and 2018 from July to October (during the rainy season). Mosquito larvae and pupae were collected from several larval pools in each site, sorted by genus before being grouped together and brought back to the field insectary for rearing into adult mosquitoes. After emerging into adults, mosquitoes were identified to species and only An. gambiae s.I. were tested.

\section{CDC Bottle bioassays}

In 2016 and 2017, pyrethroid resistance intensity was determined using Centers for Disease Control and Prevention (CDC) bottle bioassays, which involved coating $250 \mathrm{ml}$ glass bottles with $1 \times \mathbf{x}, 2 \times, 5 \times$ and $10 x$ the diagnostic concentration of permethrin (21.5, $43,107.5$ and $215 \mu \mathrm{g}$ active ingredient (ai)/bottle) and deltamethrin $(12.5,25,62.5,125 \mu \mathrm{g}$ ai/bottle) [10, 11]. For all bottle bioassay tests, a mouth aspirator was used to introduce 20-25 female An. gambiae s.l. aged 3 to 5 days into each bottle, with four bottles tested per insecticide dose. In 2018, a comparison of CDC bottle bioassay and World Health Organization (WHO) tube test for pyrethroid intensity was conducted in two sites using permethrin and deltamethrin.

Chlorfenapyr susceptibility was determined using bottles treated with $100 \mu \mathrm{g}$ ai $/ \mathrm{ml}$. At the time of testing there was no published guidance regarding chlorfenapyr susceptibility procedures or diagnostic concentrations, while work coordinated by WHO was ongoing to develop a suitable procedure. The dose of $100 \mu \mathrm{g}$ ai $/ \mathrm{ml}$ was used as an interim diagnostic concentration based on unpublished data shared between the manufacturer, BASF, PMI and CDC. Wild-caught An. gambiae s.l. from Djenné, Mopti, Bandiagara and Bankass were tested for susceptibility to chlorfenapyr. Testing was conducted simultaneously with a susceptible insectary strain (An. coluzzii Ngousso).

A bottle coated with $1 \mathrm{ml}$ acetone was used as a control. Vials of permethrin and deltamethrin technical grade active ingredient (TGAI) were provided by CDC at pre-measured concentrations for intensity tests. A vial of chlorfenapyr TGAI was provided by BASF. The diagnostic time was 30 minutes for pyrethroids, based on CDC guidelines [12]. Chlorfenapyr tests were conducted for the diagnostic time of 60 minutes, with mortality recorded every $24 \mathrm{~h}$ for $72 \mathrm{~h}$. 


\section{WHO susceptibility tube tests}

In 2018, pyrethroid resistance intensity was assessed using WHO tube tests with $\mathbf{1 x}, 5 \mathbf{x}$ and $10 \mathbf{x}$ the diagnostic concentration of alpha-cypermethrin $(0.05 \%, 0.25 \%, 0.5 \%)$, permethrin $(0.75 \%, 3.75 \%$ and $7.5 \%)$ and deltamethrin $(0.05 \%, 0.25 \%, 0.5 \%)$. Synergist assays were also conducted by pre-exposing mosquitoes to WHO papers treated with piperonyl butoxide (PBO) (4\%) for 60 minutes before being immediately transferred by mouth aspirator to a different WHO tube with a pyrethroid treated paper (alphacypermethrin $(0.05 \%)$, permethrin $(0.75 \%)$, or deltamethrin $(0.05 \%)$ ) for a further 60 minutes [13]. WHO tube tests were also performed to determine susceptibility status to bendiocarb (0.1\%) and pirimiphos-methyl (0.25\%) in 2016, 2017 and 2018.

At the time of testing there was no published guidance regarding clothianidin susceptibility procedures or diagnostic concentrations, while work coordinated by WHO was ongoing to develop a suitable protocol. Therefore, an interim protocol was developed for impregnating filter papers for tube tests. The clothianidin dosage was determined based on internal testing conducted by the manufacturer, Sumitomo Chemical Company (SCC), which showed that $1 \%$ clothianidin active ingredient provided $100 \%$ mortality against five insectary strains of An. gambiae and An. arabiensis [14]. The diagnostic dose was set at $2 \%$ weight/volume (w/v) SumiShield ${ }^{\text {TM }} 50$ WG (i.e. twice the minimum dose that killed $100 \%$ ), with distilled water used as a solvent. Clothianidin tests were conducted using filter papers prepared in Mali. A solution was prepared using $264 \mathrm{mg}$ SumiShield ${ }^{T M} 50 W G$ dissolved in $20 \mathrm{ml}$ distilled water. Whatman ${ }^{\circledR}$ No. 1 filter papers were treated using a pipette to dispense $2 \mathrm{ml}$ of solution on each 12 by $15 \mathrm{~cm}$ filter paper, resulting in a concentration of $13.2 \mathrm{mg} /$ ai clothianidin per paper. Clothianidin susceptibility testing was conducted in 2018 in four locations where IRS was conducted, namely Djenné, Mopti, Bandiagara and, Bankass (all in Mopti region).

In all tests four batches of 20-25 non blood-fed female An. gambiae s.l. adults (field collected as larvae) aged 3 to 5 days were used for the tube tests according to WHO protocols [13]. All insecticide impregnated papers (except for clothianidin, which was prepared in situ) were prepared by the WHO collaborating center, Universiti Sains, Malaysia. Knock-down was recorded at the end of the exposure period at 60 minutes. Mosquitoes were transferred into untreated observation tubes and provided with cotton wool soaked with $10 \%$ sugar solution. Mortality was recorded $24 \mathrm{~h}$ after exposure for all insecticides, except clothianidin, which was recorded daily for up to 5 days, in order to record any delayed mortality effects. Testing and holding conditions were regulated using a humidifier and air conditioner unit to stay within WHO limits of $27^{\circ} \mathrm{C} \pm 2{ }^{\circ} \mathrm{C}$ temperature and $75 \% \pm 10 \%$ relative humidity.

\section{Molecular species identification and detection of pyrethroid resistance alleles}

In 2017 and 2018, approximately 50 female An. gambiae s.I. from each site were randomly chosen from the untreated controls after CDC bottle bioassay (2017) and WHO tube test (2018), and were analyzed by PCR for species identification according to the protocol described by Santolamazza et al., 2008 [15]. This method distinguishes between An. gambiae, An. coluzzii and An. arabiensis (members of the An. gambiae s.l. species complex). Using the same mosquitoes, the frequency of the voltage-gated sodium channel ( $v g s c) 1014 \mathrm{~F}$ (previously kdrwest) and 1014S (previously kdr east) mutations was estimated according to the protocols of Martinez-Torrez [16] and Ranson [17].

\section{Data analysis and interpretation}

Resistance status of each site was determined according to the WHO criteria [13]:

Low resistance intensity: mortality $<90 \%$ at $1 \times$ diagnostic dose and between $98-100 \%$ at $5 \times$ dose. Moderate resistance intensity: mortality $<98 \%$ at the $5 \times$ dose but between $98-100 \%$ at the $10 \times$ dose. High resistance intensity: mortality $<98 \%$ at the $10 \times$ dose. The frequency of resistance mutations ( $v g s c 1014 \mathrm{~F}, 1014 \mathrm{~S})$ was determined using the formula: $\mathrm{F}=[(2 \mathrm{RR}+\mathrm{RS})] /[2(\mathrm{RR}+\mathrm{RS}+\mathrm{SS})]$. Comparison was made between mortality rates with and without PBO pre-exposure using the Chi-squared test as described by Campbell and Richardson $[18,19][16,17]$. The same methodology was used for comparison of WHO tube tests and CDC bottle bioassays in Niono and Koulikoro.

\section{Results}


Figure 2 shows mortality rates of An. gambiae s.l. following 30 minutes exposure to permethrin $10 \times(215 \mu g$ ai/bottle) and figure 3 for deltamethrin $10 \times(125 \mu \mathrm{g}(\mathrm{ai}) /$ bottle). More data are provided showing results of $1 \times, 2 \times$ and $5 \times$ as a supplementary file (Table S1). In all sites An. gambiae s.l. showed high intensity resistance to permethrin and deltamethrin in 2016 and 2017. Overall, mortality rates to permethrin 10x ranged from $28 \%$ to $93 \%$ in 2016 and from 35\% to $85 \%$ in 2017 (Figure 2). With deltamethrin 10x, mortality rates varied from $53 \%$ to $91 \%$ in 2016 and from $72 \%$ to $97 \%$ in 2017 (Figure 3 ). Mean trends showed there may have been a slight increase in permethrin resistance intensity in 2017 compared to 2016, but for deltamethrin trends were similar in 2016 and 2017.

\section{An. gambiae s.I. intensity of resistance to alpha-cypermethrin, permethrin and deltamethrin in WHO tube tests in 2018.}

Figures 4, 5 and 6 show resistance intensity results for An. gambiae s.I. against alpha-cypermethrin, permethrin, and deltamethrin at $1 \times, 5 \times$ and $10 \times$ the WHO diagnostic concentration. High intensity resistance was recorded in all sites to alphacypermethrin (mortality $<98 \%$ at $10 \times$ dose) (Figure 4 ). The mean $\%$ mortality across all sites for alpha-cypermethrin was $24.8 \%$ at $1 \times, 56.9 \%$ at $5 \times$ and $79.2 \%$ at $10 \times$ the diagnostic concentration.

Resistance intensity was also high at all sites to permethrin and deltamethrin (Figures 5 and 6 ). The mean \% mortality across all sites for permethrin was $33.6 \%$ at $1 \times, 76.9 \%$ at $5 \times$ and $90.9 \%$ at $10 \times$. For deltamethrin the mean $\%$ mortality was $49.2 \%$ at $1 \times$, $80.9 \%$ at $5 \times$ and $93.5 \%$ at $10 \times$. Crude mortality was $<98 \%$ in all sites, indicating high intensity resistance..

\section{Synergist assays using piperonyl-butoxide (PBO) and pyrethroids}

Results in Figures 7a and 7b show that overexpression of mixed function oxidases (MFOs) is an important resistance mechanism in Mali, as shown by significantly greater mortality rates after PBO pre-exposure. Figure 7a shows that pre-exposure to PBO resulted in significantly greater mortality than for permethrin alone, in 13 of 14 sites $(P<0.05)$, with Koulikoro the only site where there was no apparent response to PBO. Across all sites mean mortality was $33.7 \%$ with permethrin compared with $71.8 \%$ when pre-exposed to $\mathrm{PBO}$, representing a 2.13 fold increase in mortality $(P<0.0001)$.

Figure 7b shows that for all 14 sites there was a significant increase in mortality caused by deltamethrin following PBO pre-exposure. Although significantly increased mortality rates were obtained in nearly all sites for both insecticides after preexposure of An. gambiae s.I. to PBO, susceptibility was not fully restored in any sites. Mortality levels did increase to $>90 \%$ in two sites with PBO + permethrin (Bamako and Bla) and four sites (Niono, Bougouni, Bankass and Bamako) with PBO + deltamethrin. Across all sites mean mortality was $48.2 \%$ with deltamethrin compared with $81.3 \%$ when pre-exposed to PBO, representing a 1.69 fold increase in mortality $(P<0.0001)$.

\section{Susceptibility of $A$. gambiae s.I. to pirimiphos-methyl (0.25\%) in WHO susceptibility tube tests in 2016, 2017and 2018}

In all years, susceptibility (mortality rate $\geq 98 \%$ ) to pirimiphos-methyl $(0.25 \%)$ was observed in all sites where pirimiphos-methyl CS has previously been sprayed for malaria control, including Koulikoro, Baroueli, Djenné, Bandiagara and Bankass.

Susceptibility was also recorded in all other sites, except for Selingue, where possible resistance was noted in 2018 (96.7\% mortality) (Table 2: supplementary file).

\section{Susceptibility of An. gambiae s.I. to bendiocarb (0.1\%) in WHO susceptibility tube tests in 2016, 2017and 2018}

In 2016, susceptibility (mortality rate $\geq 98 \%$ ) was obtained with bendiocarb (0.1\%) in all sites except for Niono (95\%) and Bougouni (92\%), where possible resistance was observed. In 2017, susceptibility was observed in 5 sites (Fana, Koulikoro, Bla, Djenné and Bankass), with possible resistance (90-97\% mortality) in 4 sites (Kita, Kati, Bamako and Bandiagara) and resistance $(<90 \%)$ in 3 sites (Barouéli, Sélingué and Bougouni). In 2018, susceptibility was noted in all 6 sites where testing was conducted (Bla, Selingue, Bougouni, Djenné, Bandiagara and Bankass). Mortality rates to bendiocarb in the surveyed sites are summarized in Table 3: supplementary file.

\section{Susceptibility of An. gambiae s.l. to chlorfenapyr (100 $\mu \mathrm{g}$ ai/bottle) in CDC bottle bioassays}


Figure 8 displays mortality rates obtained 24, 48 and 72 hours after exposing An. gambiae s.l. from Djenné, Mopti, Bandiagara

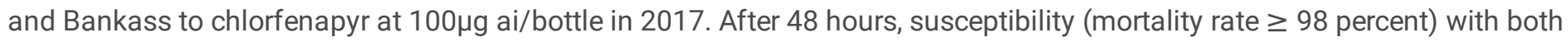
field and insectary An. coluzzii Ngousso (susceptible insectary strain) was determined at all sites, except Bandiagara. $A$. gambiae s.l. mortality was $<98 \%$ in Bandiagara after $48 \mathrm{~h}$ but did reach $98 \%$ at 72 hours (the diagnostic time). Therefore, susceptibility to chlorfenapyr was recorded in all sites within $72 \mathrm{~h}$ of exposure.

\section{Susceptibility of An. gambiae s.I. to clothianidin (2\%) in WHO susceptibility tube tests in 2018}

Figure 9 shows mortality rates following exposure to clothianidin 2\% of An. gambiae s.l. (collected as larvae) from four IRS sites (Djenné, Mopti, Bandiagara and Bankass). Parallel tests were done with the same papers using the susceptible insectary strain of An. coluzzii Ngousso. Twenty-four hours after exposure, mortality rates were $90 \%$ for the insectary strain and between $44-90 \%$ for wild An. gambiae s.l. For the insectary strain, $99 \%$ mortality was observed three days after exposure, with mortality rates slightly lower for wild An. gambiae s.I. One hundred percent mortality was recorded for insectary and wild An. gambiae s.l., five days after exposure, indicating susceptibility to clothianidin in all four IRS sites. Mortality rates in negative controls were low and varied from $0 \%$ to $10 \%$ after five days.

\section{Comparison of CDC bottle bioassays and WHO susceptibility tube tests for determining pyrethroid resistance intensity}

Figure 10 shows percentage mortality of An. gambiae s.l. to permethrin (a) and deltamethrin (b) at doses of $1 \times, 2 \times, 5 \times$ and $10 \times$ the diagnostic concentration, using both bottle bioassays (30 minutes mortality) and WHO susceptibility tube tests (24h mortality) in Koulikoro and Niono in 2018. Both methods indicate high intensity pyrethroid resistance in Koulikoro and Niono (mortality $<98 \%$ at $10 \times$ ). Testing conducted in Niono consistently produced higher mortality rates for both permethrin and deltamethrin with WHO tube tests as compared to CDC bottle bioassays at all doses $(p<0.05)$. In Koulikoro the $5 x$ and $10 x$ doses of permethrin produced higher mortality for permethrin in WHO tube tests than CDC bottle bioassay. However, there was only a difference at the $1 \times$ dose with deltamethrin in Koulikoro.

\section{Molecular species identification of the An. gambiae species complex}

In 2017 and 2018, adult An. gambiae s.I. specimens (collected as larvae) used for susceptibility tests from sentinel sites (approx. 50 mosquitoes/site) located in 6 regions (Figure 1), were tested by PCR for species identification. Figure 11 summarizes $A n$. gambiae s.l. sibling species composition by region and L1014F/S frequency. An. coluzzii was the primary vector in 4 regions (Koulikoro, Ségou, Mopti and Bamako) in 2017 and 2018. In the southern region of Sikasso, slightly more than half were $A n$. gambiae, with just over $40 \%$ being An. coluzzii in both years. Some hybrid samples (gambiae/coluzzii) were recorded at low frequency ( $\leq 2 \%$ by region).

In Kayes Region, the composition changed from predominantly An. gambiae in 2017 to An. arabiensis in 2018. However, the sites in the region changed during this period with Kita maintained in both years and the western Kayes site (Figure 1) only surveyed during 2018 (which accounted for most An. arabiensis). An. arabiensis was present at relatively low frequency in all other regions (2-10\%). Between 3-24\% of samples did not amplify by PCR using primers of the An. gambiae s.l. complex. Samples may not have amplified due to degraded DNA or due to morphological mis-identification (non An. gambiae s.I.).

The frequency of $v g s c-1014 \mathrm{~F}$ and 1014S alleles are summarized as tables in Figure 11 for the main vector species of each region. In 2017, the vgsc-1014S allele was absent in most regions, only being detected at a frequency of 0.01 in Koulikoro. The $v g s c 1014 \mathrm{~F}$ allele was present at moderate to high frequency in all regions for An. gambiae (0.47-0.95) than An. coluzzii (0.58-0.77).

\section{Discussion}

Pyrethroid resistance has been widespread in Mali for several years. A study by Cisse et al. in 2012 showed An. gambiae s.l. were resistant to lambda-cyhalothrin in all 9 sites tested and to deltamethrin in 3 of 4 sites [9]. The vgsc-1014F mutation, which is associated with pyrethroid resistance, has been present in An. gambiae s.I. in Mali since 1987 (albeit at low frequency) [20]. Fanello et al. showed that vgsc-1014F increased in frequency in Banambani (Koulikoro Region) from 3\% in 1987 to $62 \%$ in 2000 , 
presumably due to an increase in selection pressure from agriculture and early Insecticide Treated Net (ITN) use [20]. The gradual increase in vgsc-1014F frequency in Mali was also reported by Tripet et al., 2007 [21].

While pyrethroid resistance has been present for $>20$ years in malaria vectors throughout Mali [20] it is not clear to what extent LLIN efficacy has been compromised. Numerous small scale studies in sub-Saharan Africa have demonstrated reduced control of resistant malaria vectors by pyrethroid LLINs $[8,22,23]$. A multi-country evaluation coordinated by WHO provided evidence that LLINs continue to provide some degree of personal protection against malaria in areas with pyrethroid resistance, but did not monitor community impact caused by the mosquito killing effect of LLINs [24].The World Malaria Report (2018) noted that global progress against malaria has stalled, with no significant progress in reducing global malaria cases made between 20152017, with a possible explanation being the widespread occurrence of pyrethroid resistant malaria vectors [25].

The concept of resistance intensity is relatively new, having first been included in WHO testing guidelines in 2016 [13]. Nevertheless, high intensity pyrethroid resistance is being reported in an increasing number of locations, including Accra in Ghana [26], Lagos and Ogun in Nigeria [27], western Kenya [28] and south-western Burkina Faso [29]. Despite uncertainty regarding the impact of pyrethroid resistance, WHO states that, "when resistance is confirmed at the $5 \times$ and especially at the 10x concentrations, operational failure is likely"[13]. Throughout Mali, resistance to the 3 most common pyrethroids used on LLINs was confirmed at the $5 \times$ and $10 \times$ concentrations, therefore making it highly likely that pyrethroid LLINs are no longer providing optimal protection against malaria. High intensity pyrethroid resistance appears to be present in all three major malaria vector species in Mali, with An. arabiensis in Kayes region, An. gambiae s.s. in Sikasso region and An. coluzzii in Koulikoro, Segou, Bamko and Mopti regions exhibiting high intensity resistance to permethrin, deltamethrin and alpha-cypermethrin.

In Koulikoro and Niono, where CDC bottle bioassays as well as WHO susceptibility tube tests were used simultaneously, high intensity pyrethroid resistance was observed for both methods. However, in most cases, significantly higher mortality rates were observed in WHO tube tests than in CDC bottle bioassays. Owusu et al., 2015 concluded that the two assays can both successfully detect insecticide resistance, but there was a high level of inconsistency between the two methods when using the diagnostic concentration [30]. There are pros and cons to both methods for determining resistance intensity. In this study a decision was made to switch from CDC bottle bioassays to WHO papers due to the ease of use and standardized provision of treated filter papers from WHO, compared to self-treatment of bottles which may result in more technician-induced test variation.

Unlike in previous years, there are an increasing number of LLIN options for the control of pyrethroid resistant malaria vectors, including several brands of PBO synergist nets (involving mixtures of PBO plus permethrin, deltamethrin or alpha-cypermethrin). There are also LLINs that contain new insecticides for malaria vector control, such as Interceptor $\mathrm{G} 2{ }^{\circledR}$, a mixture of chlorfenapyr (pyrrole) and alpha-cypermethrin (pyrethroid), while Olyset Duo ${ }^{\circledR}$ and Royal Guard ${ }^{\circledR}$, are both mixtures of pyriproxyfen (juvenile hormone mimic) plus a pyrethroid. The main factors limiting the uptake of these alternative products are the increased cost and a lack of epidemiological evidence to show improved performance over pyrethroid nets. Preliminary results show susceptibility to chlofenapyr in Mali. As part of the 'New Nets Project' 2 million Interceptor G2 nets are being distributed in several countries, including Mali in 2020 as an operational pilot to build evidence regarding the cost-effectiveness of dual active ingredient nets [31].

Results of synergist bioassays in Mali indicated that metabolic resistance is present nationwide and pre-exposure to PBO increased pyrethroid-induced mortality significantly. Full susceptibility was not recovered using PBO, indicating a combination of resistance mechanisms, with high vgsc-1014F frequencies in An. coluzzii and An. gambiae. In Tanzania, use of PBO LLINs resulted in reduced malaria incidence compared to standard pyrethroid LLINs [32]. However, it is not clear what level of mortality is required in PBO bioassays to result in epidemiological impact as there was no bioassay data in the Tanzania study. Synergist bioassays in Mali suggest that PBO LLINs should provide better control than pyrethroid LLINs, although the epidemiological impact is uncertain. A previous published study by Cisse et al., 2017 appeared to show no benefit of PBO LLINs in Bougouni, Mali [33]. However this study was conducted in 2014 in a location where synergist bioassays showed much lower metabolic resistance levels [9]. A study by Protopopoff et al. (2018) in Tanzania showed that PBO LLINs improved control of malaria transmission compared to standard pyrethroid LLINs, but there was no additional benefit of non-pyrethroid IRS combined with 
PBO LLINs when compared to PBO LLINs alone [32]. While more epidemiological studies are needed, this finding suggests that PBO and next generation LLINs should be prioritized for non IRS areas.

Pyrethroid insecticides have not been used for IRS in Mali since 2009, when resistance was detected. The good news is that there are viable options for IRS in Mali, with susceptibility recorded to clothianidin and pirimiphos-methyl. The PMI VectorLink program is currently implementing IRS in Mopti Region of Mali with these products in rotation for resistance management.

\section{Conclusions}

High intensity pyrethroid resistance is widespread in Mali and threatens the efficacy of pyrethroid LLINs. Synergist bioassays suggest that PBO LLINs should provide improved control in most districts of Mali. An. gambiae s.l. was susceptibile to chlorfenapyr, indicating that next generation LLINs are also a viable alternative. Susceptibility to clothianidin and pirimiphosmethyl was confirmed, with both insecticides currently being used for IRS as part of a rotation strategy for resistance management.

\section{Abbreviations}

Al: active ingredient

BASF: Badische Anilin und Soda Fabrik

CDC: United States Centers for Disease Control and Prevention

CS: capsule suspension

DHS: demographic and health survey

IRS: indoor residual spraying

ITN: insecticide treated net

LLIN: long lasting insecticidal net

NMCP: National Malaria Control Program

PBO: piperonyl butoxide

PCR: polymerase chain reaction

PMI: United States President's Malaria Initiative

TGAI: technical grade active ingredient

SCC: Sumitomo Chemical Company

VGSC: voltage gated sodium channel

WHO: World Health Organization

WG: water dispersible granules

WP: Wettable powder

\section{Declarations}


The technicians who conducted mosquito collections and bioassays are thanked for their dedicated work. We thank CDC, WHO, BASF and Sumitomo Chemical Company (SCC) for provision of insecticide for susceptibility testing.

\section{Declarations}

\section{Ethics approval and consent to participate}

The trial protocol was reviewed and approved by the Ethical Committee of the

Department of Pharmacy and Dentistry (FMPOS), Ministry of Higher Education

and Scientific Research, Mali.

\section{Consent for publication}

Not applicable.

\section{Availability of data and materials}

The datasets used and/or analyzed during the current study are available from the corresponding author on reasonable request.

\section{Competing interests}

The authors declare that they have no competing interests.

\section{Funding}

This study was supported by the United States President's Malaria Initiative through the United States Agency for International Development Africa Indoor Residual Spraying (AIRS) and VectorLink Projects. The opinions expressed herein are those of the authors and do not necessarily reflect the views of USAID, PMI or CDC.

\section{Authors' contributions}

AS was involved in the design of the study, supervised data collection, interpreted data, conducted analysis and wrote the manuscript draft.

$C K, Y S$ and $A D$ supervised field data collection and data entry.

IT, MB, MC and OK conducted and supervised collection of molecular data.

$\mathrm{DD}, \mathrm{CF}, \mathrm{EB}, \mathrm{JM}, \mathrm{KG}, \mathrm{JC}$ and $\mathrm{CF}$ provided programmatic support and reviewed the manuscript.

RMO was involved in the design of the study, provided remote technical support, interpreted data, conducted analysis and provided substantial editing of the manuscript.

All authors read and approved the final manuscript.

\section{References}

1. INSTAT: Enquête Démographique et de Santé 2018. 2019.

2. PMI: President's Malaria Initiative; Mali Malaria Operational Plan (MOP) FY 2008. 2008.

3. Wagman J, Gogue C, Tynuv K, Mihigo J, Bankineza E, Bah M, et al. An observational analysis of the impact of indoor residual spraying with non-pyrethroid insecticides on the incidence of malaria in Segou Region, Mali: 2012-2015. Malar J. 2018;17 1:19; 
4. Programme National de Lutte contre le Paludisme (PNLP). Enquête sur les Indicateurs du Paludisme au Mali (EIPM) 2015. 2015.

5. Lengeler C. Insecticide-treated bed nets and curtains for preventing malaria. Cochrane Database Syst Rev. 2004; 2:CD000363;

6. Pluess B, Tanser FC, Lengeler C, Sharp BL. Indoor residual spraying for preventing malaria. Coch Data Syst Rev. 2010;NA 4:1-47;

7. Ranson $\mathrm{H}$, Lissenden $\mathrm{N}$. Insecticide resistance in African Anopheles mosquitoes: A worsening situation that needs urgent action to maintain malaria control. Trends Parasitol. 2016;32 3:187-96;

8. N'Guessan R, Corbel V, Akogbeto M, Rowland M. Reduced efficacy of insecticide-treated nets and indoor residual spraying for malaria control in pyrethroid resistance area, Benin. Emerg Infect Dis. 2007;13 2:199-206;

9. Cisse MB, Keita C, Dicko A, Dengela D, Coleman J, Lucas B, et al. Characterizing the insecticide resistance of Anopheles gambiae in Mali. Malar J. 2015;14:327;

10. Brogdon WG, Chan A: Guideline for Evaluating Insecticide Resistance in Vectors Using the CDC Bottle Bioassay. 2010.

11. Brogdon WG, Chan A: Insert 2 - Enhanced Surveillance Protocol for the CDC Intensity Bottle Bioassay - 2013 Guideline for Evaluating Insecticide Resistance in Vectors Using the CDC Bottle Bioassay.

12. CDC. Bottle Bioassays. http://wwwcdcgov/ncidod/wbt/resistance/assay/bottle/indexhtm

13. WHO. Test procedures for insecticide resistance monitoring in malaria vector mosquitoes, second edition. WHO Library. 2016.

14. Oxborough R, Seyoum A, Yihdego Y, Dabire KR, Gnanguenon V, Watsenga Tezzo F, et al. Susceptibility testing of Anopheles malaria vectors with the neonicotinoid insecticide clothianidin; results from 16 African countries, in preparation for indoor residual spraying with new insecticide formulations. Malar J. 2019.

15. Santolamazza F, Mancini E, Simard F, Qi Y, Tu Z, della Torre A. Insertion polymorphisms of SINE200 retrotransposons within speciation islands of Anopheles gambiae molecular forms. Malar J. 2008;7:163;

16. Martinez-Torres D, Chandre F, Williamson MS, Darriet F, Berge JB, Devonshire AL, et al. Molecular characterization of pyrethroid knockdown resistance (kdr) in the major malaria vector Anopheles gambiae s.s. Insect Mol Biol. 1998;7 2:179-84;

17. Ranson H, Jensen B, Vulule JM, Wang X, Hemingway J, Collins FH. Identification of a point mutation in the voltage-gated sodium channel gene of Kenyan Anopheles gambiae associated with resistance to DDT and pyrethroids. Insect Mol Biol. 2000;9 5:491-7.

18. Campbell I. Chi-squared and Fisher-Irwin tests of two-by-two tables with small sample recommendations. Stat Med. 2007;26 19:3661-75;

19. Richardson JT. The analysis of 2 x 2 contingency tables-yet again. Stat Med. 2011;30 8:890; author reply 1-2;

20. Fanello C, Petrarca V, della Torre A, Santolamazza F, Dolo G, Coulibaly M, et al. The pyrethroid knock-down resistance gene in the Anopheles gambiae complex in Mali and further indication of incipient speciation within An. gambiaes.s. Insect Mol Biol. 2003;12 3:241-5.

21. Tripet F, Wright J, Cornel A, Fofana A, McAbee R, Meneses C, et al. Longitudinal survey of knockdown resistance to pyrethroid (kdr) in Mali, West Africa, and evidence of its emergence in the Bamako form of Anopheles gambiae s.s. The American journal of tropical medicine and hygiene. 2007;76 1:81-7.

22. Asidi A, N'Guessan R, Akogbeto M, Curtis $C$, Rowland M. Loss of household protection from use of insecticide-treated nets against pyrethroid-resistant mosquitoes, benin. Emerg Infect Dis. 2012;18 7:1101-6;

23. Agossa FR, Gnanguenon V, Anagonou R, Azondekon R, Aizoun N, Sovi A, et al. Impact of Insecticide Resistance on the Effectiveness of Pyrethroid-Based Malaria Vectors Control Tools in Benin: Decreased Toxicity and Repellent Effect. PLoS One. 2015;10 12:e0145207;

24. World Health Organization. WHO-Coordinated multi-country evaluation. Implications of insecticide resistance for malaria vector control 2016;WHO/HTM/GMP/2016.8.rev.

25. WHO: World Malaria Report, 2018.

Page $11 / 24$ 
26. Pwalia R, Joannides J, Iddrisu A, Addae C, Acquah-Baidoo D, Obuobi D, et al. High insecticide resistance intensity of Anopheles gambiae (s.I.) and low efficacy of pyrethroid LLINs in Accra, Ghana. Parasit Vectors. 2019;12 1:299;

27. Awolola TS, Adeogun A, Olakiigbe AK, Oyeniyi T, Olukosi YA, Okoh H, et al. Pyrethroids resistance intensity and resistance mechanisms in Anopheles gambiae from malaria vector surveillance sites in Nigeria. PLoS One. 2018;13 12:e0205230;

28. Omondi S, Mukabana WR, Ochomo E, Muchoki M, Kemei B, Mbogo C, et al. Quantifying the intensity of permethrin insecticide resistance in Anopheles mosquitoes in western Kenya. Parasit Vectors. 2017;10 1:548;

29. Toe KH, Jones CM, N'Fale S, Ismail HM, Dabire RK, Ranson H. Increased pyrethroid resistance in malaria vectors and decreased bed net effectiveness, Burkina Faso. Emerg Infect Dis. 2014;20 10:1691-6;

30. Owusu HF, Jancaryova D, Malone D, Muller P. Comparability between insecticide resistance bioassays for mosquito vectors: time to review current methodology? Parasit Vectors. 2015;8:357;

31. BASF: Building a stronger line of defense against malaria. https://agriculture.basf.com/en/Pest-Control/Commitment-toPublic-Health/The-New-Nets-Project.html (2019). Accessed 29/06/2019 2019.

32. Protopopoff N, Mosha JF, Lukole E, Charlwood JD, Wright A, Mwalimu CD, et al. Effectiveness of a long-lasting piperonyl butoxide-treated insecticidal net and indoor residual spray interventions, separately and together, against malaria transmitted by pyrethroid-resistant mosquitoes: a cluster, randomised controlled, two-by-two factorial design trial. Lancet. 2018;391 10130:1577-88;

33. Cisse MBM, Sangare D, Oxborough RM, Dicko A, Dengela D, Sadou A, et al. A village level cluster-randomized entomological evaluation of combination long-lasting insecticidal nets containing pyrethroid plus PBO synergist in Southern Mali. Malar J. 2017;16 1:477;

\section{Table}

Table 1: Characteristics of surveillance sites used for insecticide resistance monitoring.

\begin{tabular}{|c|c|c|}
\hline Regions & Districts & History of Insecticide Use \\
\hline \multirow[t]{2}{*}{ Kayes } & Kayes & \multirow{2}{*}{$\begin{array}{l}\text { Intense use of insecticides for agriculture. } \\
\text { Crops include cotton and ground nuts, sorghum, maize, rice, millet, sweet potatoes, } \\
\text { beans and various vegetables. }\end{array}$} \\
\hline & Kita & \\
\hline \multirow[t]{3}{*}{ Koulikoro } & Koulikoro & $\begin{array}{l}\text { Annual IRS with lambda-cyhalothrin (pyrethroid) 2008-2011, bendiocarb } \\
\text { (carbamate) 2011-2014 and pirimiphos-methyl (organophosphate) 2014-2016. }\end{array}$ \\
\hline & Fana & Single round of IRS with pirimiphos-methyl (organophosphate) in 2016. \\
\hline & Kati & $\begin{array}{l}\text { Irrigated agriculture including cotton, groundnuts and tobacco. Use of insecticides } \\
\text { to control Simulium damnosum larvae (black fly). }\end{array}$ \\
\hline \multirow[t]{3}{*}{ Segou } & Niono & Large areas of irrigated rice agriculture and pesticide use. \\
\hline & Bla & IRS with pirimiphos-methyl (organophosphate) in 2014. \\
\hline & Baroueli & $\begin{array}{l}\text { Annual IRS with lambda-cyhalothrin (pyrethroid) 2008-2011, bendiocarb } \\
\text { (carbamate) 2011-2014 and pirimiphos-methyl (organophosphate) 2014-2016. }\end{array}$ \\
\hline \multirow[t]{2}{*}{ Sikasso } & Bougouni & Intense use of insecticides for growing of cotton. \\
\hline & $\begin{array}{l}\text { Sélingué } \\
\text { Kadiolo }\end{array}$ & $\begin{array}{l}\text { Irrigated agriculture and pesticide use. Crops include various vegeratables and } \\
\text { fruits. }\end{array}$ \\
\hline \multirow[t]{4}{*}{ Mopti } & Bandiangara & \multirow[t]{3}{*}{ IRS with pirimiphos-methyl in 2017 and 2018.} \\
\hline & Mopti & \\
\hline & Bankass & \\
\hline & Djenné & IRS with pirimiphos-methyl in 2017 and clothianidin in 2018. \\
\hline Bamako & Bamako & $\begin{array}{l}\text { Urban areas where domestic personal protection is used (insecticide aerosols, } \\
\text { coils). }\end{array}$ \\
\hline
\end{tabular}

\section{Additional Files}


Additional file 1: Table S1. Percentage mortality of An. gambiae s.l. tested with permethrin and deltamethrin in 2016 and 2017 at $1 \times, 5 \times$ and 10x the diagnostic concentraion in CDC bottle intensity bioassays.

\begin{tabular}{|c|c|c|c|c|c|c|c|c|c|c|c|c|c|c|c|c|}
\hline \multirow[t]{2}{*}{ Sites } & \multicolumn{4}{|c|}{ Permethrin 2016} & \multicolumn{4}{|c|}{ Permethrin 2017} & \multicolumn{4}{|c|}{ Deltamethrin 2016} & \multicolumn{4}{|c|}{ Deltamethrin 2017} \\
\hline & $1 \mathrm{X}$ & $5 X$ & $10 \mathrm{X}$ & \begin{tabular}{|l|} 
Intensity \\
of \\
resistance
\end{tabular} & $1 \mathrm{X}$ & $5 \mathrm{X}$ & $10 \mathrm{X}$ & $\begin{array}{l}\text { Intensity } \\
\text { of } \\
\text { resistance }\end{array}$ & $1 \mathrm{X}$ & $5 \mathrm{X}$ & 10X & $\begin{array}{l}\text { Intensity } \\
\text { of } \\
\text { resistance }\end{array}$ & 1X & $5 \mathrm{X}$ & $10 \mathrm{X}$ & $\begin{array}{l}\text { Intensity } \\
\text { of } \\
\text { resistance }\end{array}$ \\
\hline Djénné & 17 & 27 & 28 & High & 05 & 38 & 66 & High & 38 & 60 & 53 & High & 11 & 71 & 75 & High \\
\hline Mopti & - & - & - & - & 06 & 36 & 54 & High & - & - & - & - & 29 & 83 & 91 & High \\
\hline Bandiagara & 19 & 49 & 69 & High & 26 & 58 & 72 & High & 38 & 87 & 78 & High & 41 & 69 & 94 & High \\
\hline Bankass & 42 & 81 & 75 & $\overline{\text { High }}$ & 02 & 40 & 60 & $\overline{\text { High }}$ & 43 & 74 & 83 & $\overline{\text { High }}$ & 22 & 72 & 81 & $\overline{\text { High }}$ \\
\hline Koulikoro & 34 & 92 & 91 & High & 06 & 59 & 80 & High & 2 & 84 & 81 & High & 26 & 55 & 72 & High \\
\hline Fana & 18 & 36 & 66 & High & 12 & 55 & 66 & High & 21 & 48 & 76 & High & 36 & 70 & 74 & High \\
\hline Baroueli & 03 & 30 & 93 & High & 10 & 17 & 55 & High & 39 & 71 & 89 & High & 12 & 65 & 82 & High \\
\hline Bamako & 34 & 36 & 74 & High & 00 & 47 & 63 & High & 84 & 80 & 90 & High & 7 & 54 & 86 & High \\
\hline Kati & 78 & 86 & 91 & High & 06 & 40 & 68 & High & 84 & 61 & 88 & High & 26 & 61 & 83 & High \\
\hline Bla & 20 & 88 & 88 & High & 12 & 68 & 74 & High & 64 & 74 & 88 & High & 18 & 76 & 87 & High \\
\hline Selingue & 04 & 29 & 44 & High & 05 & 24 & 64 & High & 23 & 51 & 64 & High & 11 & 43 & 86 & High \\
\hline Bougouni & 09 & 17 & 83 & High & 16 & 28 & 35 & High & 43 & 92 & 88 & High & 14 & 35 & 80 & High \\
\hline Niono & 16 & - & 93 & High & 05 & 43 & 63 & High & - & - & - & - & 26 & 69 & 81 & High \\
\hline Kita & 47 & 64 & 64 & $\overline{\text { High }}$ & 04 & 35 & 60 & $\overline{\text { High }}$ & 62 & 77 & 71 & $\overline{\text { High }}$ & 11 & 58 & 78 & $\overline{\text { High }}$ \\
\hline Kadiolo & 07 & 43 & 61 & High & 06 & 71 & 85 & High & 55 & 90 & 91 & High & 74 & 87 & 97 & High \\
\hline Mean & 21 & 52 & 73 & High & 08 & 44 & 64 & High & 46 & 73 & 80 & High & 24 & 65 & 83 & High \\
\hline
\end{tabular}

Additional file 1: Table S2. Mortality of An. gambiae s.l. tested with $0.25 \%$ pirimiphos-methyl in 2016,2017 \& 2018.

\begin{tabular}{|c|c|c|c|c|c|c|}
\hline & Pirimi] & nethyl (0.25\%) & & & & \\
\hline & 2016 & & 2017 & & 2018 & \\
\hline Sites & $\begin{array}{l}\text { Total } \\
\text { tested }\end{array}$ & $\begin{array}{l}\text { Mortality (\%) } \\
\text { Resistance } \\
\text { Status }\end{array}$ & $\begin{array}{l}\text { Total } \\
\text { tested }\end{array}$ & $\begin{array}{l}\text { Mortality (\%) } \\
\text { Resistance } \\
\text { Status }\end{array}$ & $\begin{array}{c}\text { Total } \\
\text { tested }\end{array}$ & $\begin{array}{l}\text { Mortality (\%) } \\
\text { Resistance } \\
\text { Status }\end{array}$ \\
\hline Kita & 100 & $100 \_S$ & 97 & $100 \_S$ & 94 & $100 \_S$ \\
\hline Fana & 100 & $100 \_S$ & 97 & $100 \_S$ & - & - \\
\hline Koulikoro & 103 & $100 \_S$ & 100 & $100 \_S$ & 92 & 100 _S \\
\hline Kati & 100 & $100 \_S$ & 102 & $100 \_S$ & 100 & $98 \_S$ \\
\hline Bamako & 100 & $100 \_S$ & 100 & $100 \_S$ & 100 & $100 \_S$ \\
\hline Bla & 100 & 99 _S & 100 & $100 \_S$ & 100 & $100 \_S$ \\
\hline Baroueli & 100 & $100 \_S$ & 100 & $100 \_S$ & - & - \\
\hline Niono & - & - & - & - & - & - \\
\hline Selingue & 100 & $100 \_\mathrm{S}$ & 100 & $100 \_S$ & 91 & 96.7 PR \\
\hline Bougouni & 81 & $100 \_S$ & 100 & $100 \_S$ & 100 & $100 \_S$ \\
\hline Kadiolo & 100 & $100 \_S$ & - & - & 100 & 99 _S \\
\hline Djenné & 94 & 100 _S & 100 & $100 \_S$ & 100 & 100 _S \\
\hline Bandiagara & 104 & $100 \_S$ & 100 & $100 \_S$ & 100 & $100 \_S$ \\
\hline Bankass & 104 & $100 \_S$ & 102 & $100 \_S$ & 100 & $100 \_S$ \\
\hline Total & 1286 & 99.9_S & 1198 & $100 \_\mathrm{S}$ & 1077 & 99.4 _S \\
\hline
\end{tabular}

S: Susceptible, PR: Possible Resistance, R: Resistant

Additional file 1: Table S3. Mortality of An. gambiae s.l. tested with 0.1\% Bendiocarb in 2016, $2017 \& 2018$ 


\begin{tabular}{|c|c|c|c|c|c|c|c|c|c|}
\hline \multirow[b]{3}{*}{ Sites } & \multicolumn{9}{|c|}{ Bendiocarb (0.1\%) } \\
\hline & \multicolumn{3}{|l|}{2016} & \multicolumn{3}{|l|}{2017} & \multicolumn{3}{|l|}{2018} \\
\hline & $\begin{array}{l}\text { Total } \\
\text { tested }\end{array}$ & $\begin{array}{l}\text { Mortality } \\
(\%) \\
\text { Resistance } \\
\text { Status }\end{array}$ & $\mathrm{CI}$ & $\begin{array}{l}\text { Total } \\
\text { tested }\end{array}$ & $\begin{array}{l}\text { Mortality (\%) } \\
\text { Resistance } \\
\text { Status }\end{array}$ & CI & $\begin{array}{l}\text { Total } \\
\text { tested }\end{array}$ & $\begin{array}{l}\text { Mortality } \\
\text { (\%)_Resistance } \\
\text { Status }\end{array}$ & CI \\
\hline Kita & 100 & 100_S & - & 100 & 95_PR & $\begin{array}{l}{[90.7-} \\
99.3]\end{array}$ & - & - & - \\
\hline Fana & 100 & 100_S & - & 102 & 98_S & $\begin{array}{l}{[95.3-} \\
100]\end{array}$ & - & - & - \\
\hline Koulikoro & 104 & 99_S & $\begin{array}{l}{[97.2-} \\
100]\end{array}$ & 100 & 99_S & $\begin{array}{l}{[97-} \\
100]\end{array}$ & - & - & - \\
\hline Kati & 100 & 98_S & $\begin{array}{l}{[95.3-} \\
100]\end{array}$ & 100 & 97_PR & $\begin{array}{l}{[93.7-} \\
100]\end{array}$ & - & - & - \\
\hline Bamako & 100 & 98_S & $\begin{array}{l}{[95.3-} \\
100]\end{array}$ & 100 & 90_PR & $\begin{array}{l}\text { [84.1- } \\
95.9]\end{array}$ & - & - & - \\
\hline Bla & 100 & 100_S & - & 100 & 98_S & $\begin{array}{l}{[95.3-} \\
100]\end{array}$ & 100 & 100_S & - \\
\hline Baroueli & 100 & 98_S & $\begin{array}{l}\text { [95.3- } \\
100]\end{array}$ & 100 & 89_R & $\begin{array}{l}{[82.9-} \\
95.1]\end{array}$ & - & - & - \\
\hline Niono & 75 & 95_PR & $\begin{array}{l}\text { [89.6- } \\
99.8]\end{array}$ & - & - & - & - & - & - \\
\hline Selingue & 98 & 100_S & - & 99 & 86(R) & $\begin{array}{l}{[79-} \\
92.7]\end{array}$ & 80 & 100_S & - \\
\hline Bougouni & 100 & 92_PR & $\begin{array}{l}{[86.7-} \\
97.3]\end{array}$ & 100 & $76(\mathrm{R})$ & $\begin{array}{l}{[67.6-} \\
84.4]\end{array}$ & 100 & 100_S & - \\
\hline Kadiolo & 100 & 100_S & - & - & - & - & - & - & - \\
\hline Djenne & 100 & 100_S & - & 100 & 98_S & $\begin{array}{l}{[95.3-} \\
100]\end{array}$ & 100 & 100_S & - \\
\hline Bandiagara & 104 & 100_S & - & 100 & 97_PR & $\begin{array}{l}{[93.7-} \\
100]\end{array}$ & 100 & 100_S & - \\
\hline Bankass & 104 & 100_S & - & 87 & 99_S & $\begin{array}{l}{[96.6-} \\
100]\end{array}$ & 100 & 100_S & - \\
\hline Total & 1385 & 99_S & $\begin{array}{l}{[98-} \\
99.2]\end{array}$ & 1188 & 93_PR & $\begin{array}{l}{[92-} \\
94.8]\end{array}$ & 580 & 100_S & - \\
\hline
\end{tabular}

S: Susceptible, PR: Possible Resistance, R: Resistant

Figures 
Insecticide resistance monitoring sites

\section{Legend}

- Monitoring Sites

Regions

$\square$ BAMAKO

$\square$ GAO

$\square$ KAYES

KIDAL

KOULIKORO

$\square$ MOPTI

$\square$ SEGOU

$\square$ SIKASSO

TOMBOUCTOU

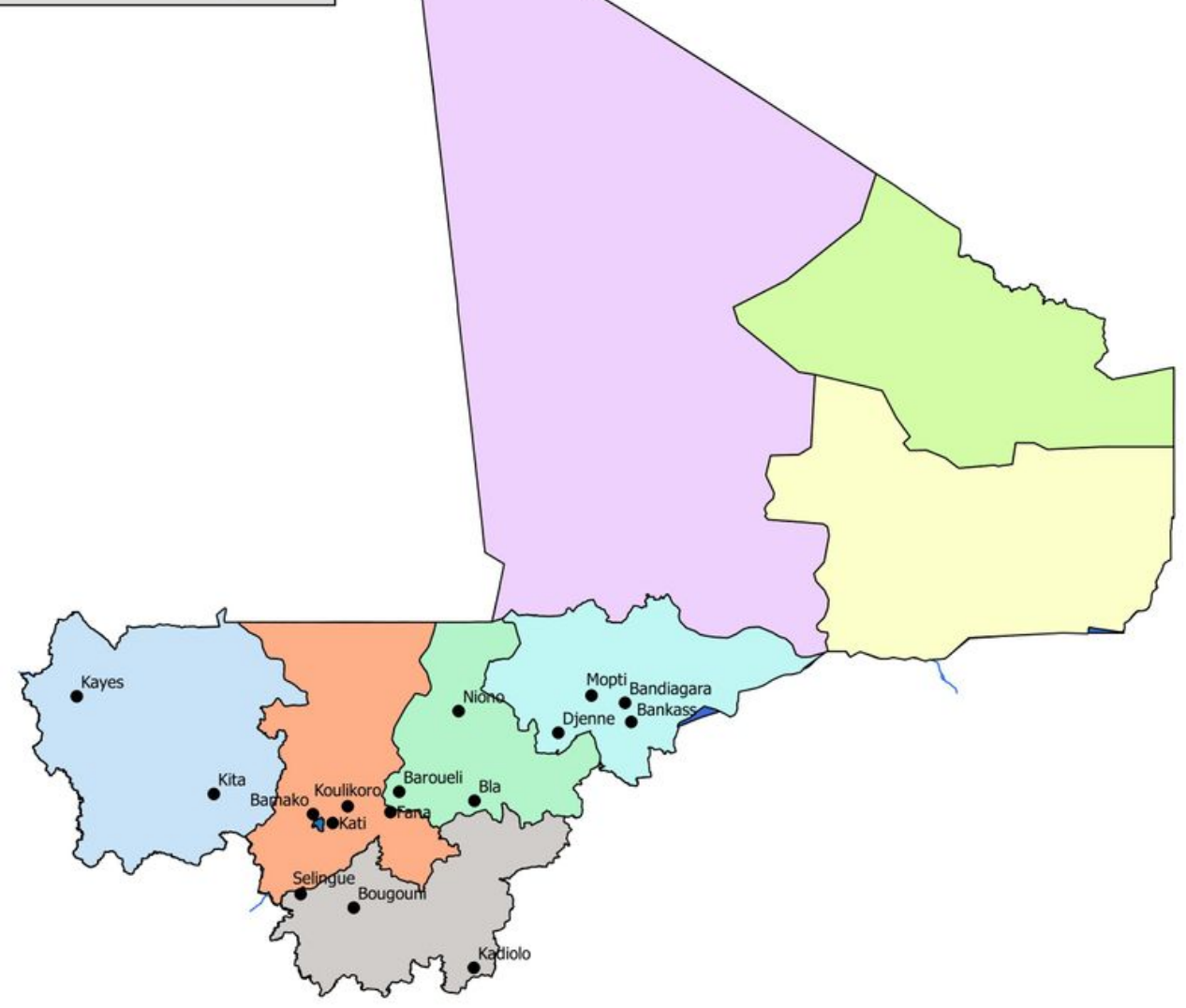

250

0

250

500

750

$1000 \mathrm{~km}$

Figure 1

Map of Mali showing the insecticide monitoring sites. 


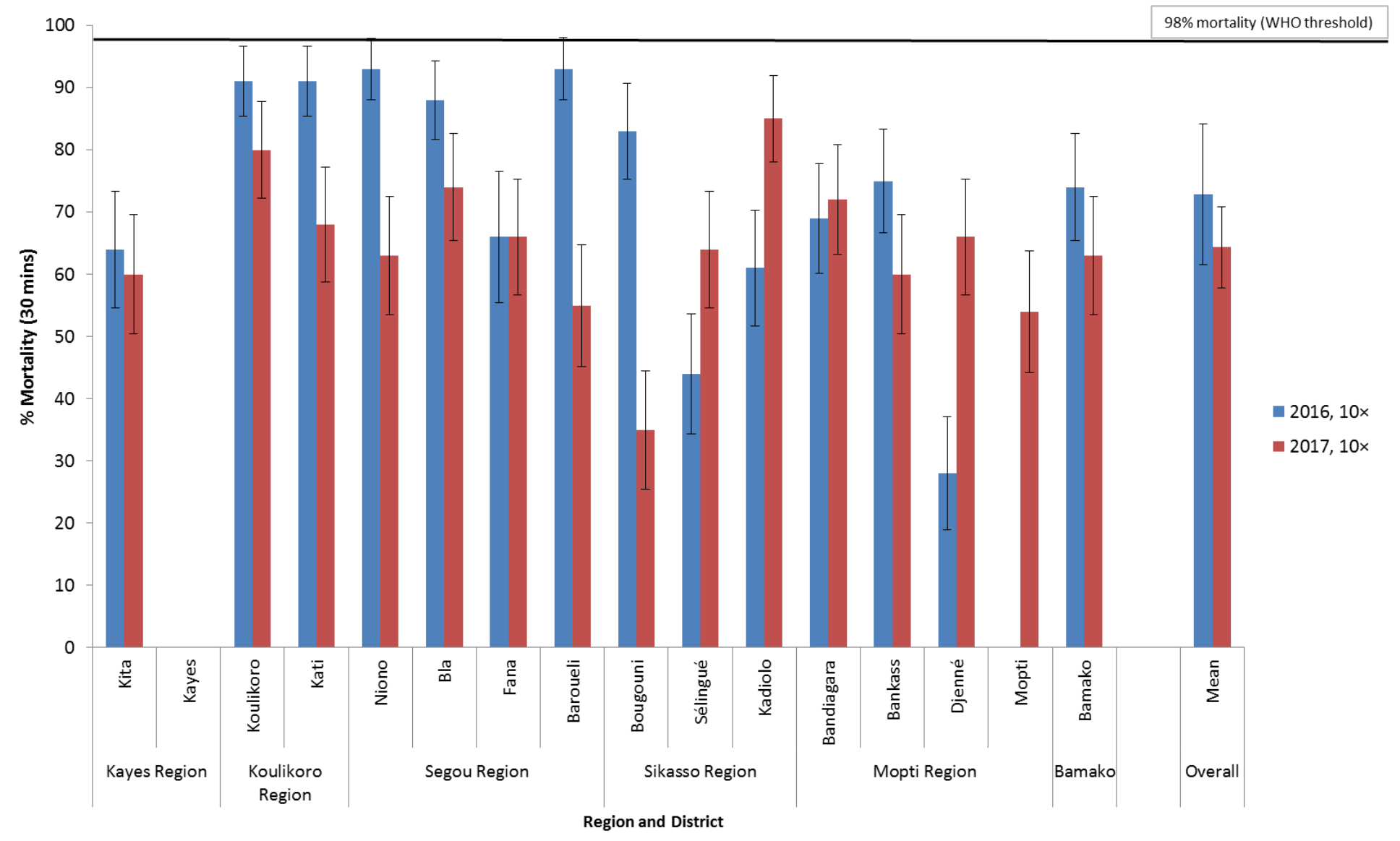

Figure 2

$\%$ Mortality of An. gambiae s.I. after 30 minute exposure to 10x the diagnostic concentration of permethrin (215 $\mu$ g ai/bottle) in CDC bottle bioassays in 2016 and 2017(NA=No data). 


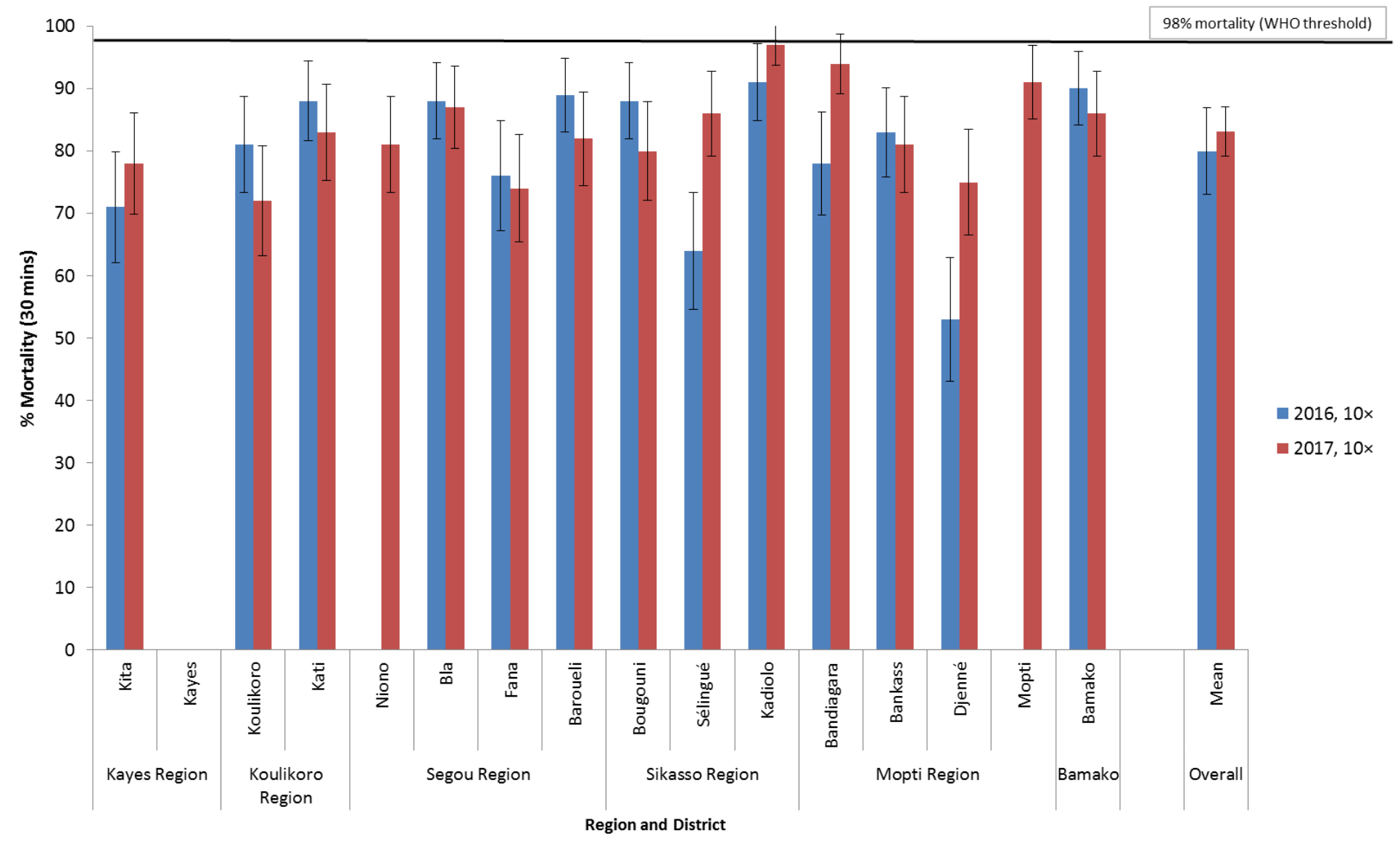

Figure 3

$\%$ Mortality of An. gambiae s.I. after 30 minute exposure to 10x the diagnostic concentration of deltamethrin (125 $\mu$ g ai/bottle) in bottle bioassays in 2016 and 2017(NA=No data). 


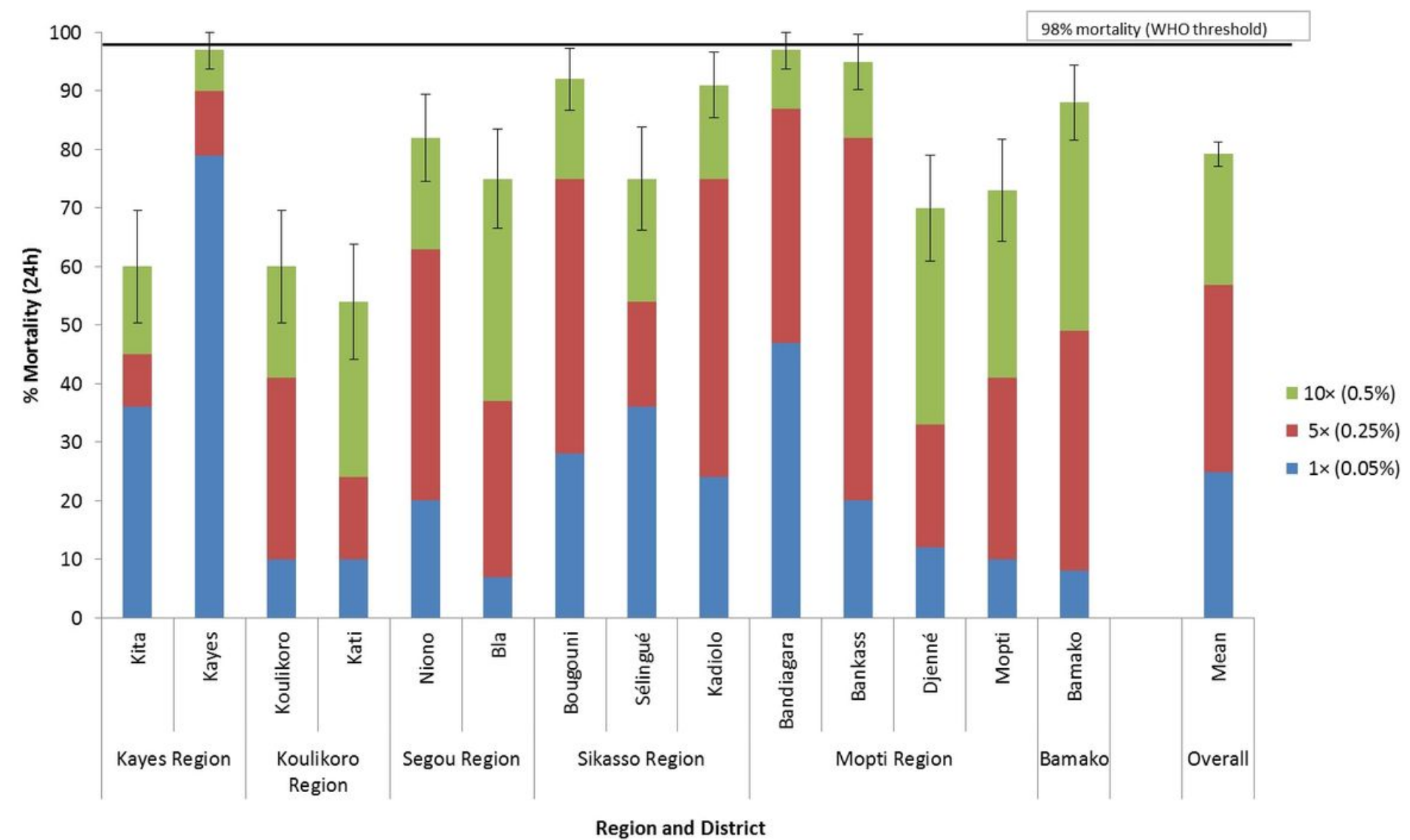

Figure 4

$\%$ Mortality of An. gambiae s.I. tested in WHO tube tests using $1 \times(0.05 \%), 5 \times(0.25 \%)$ and $10 \times(0.50 \%)$ the diagnostic concentration of alpha-cypermethrin in 2018.

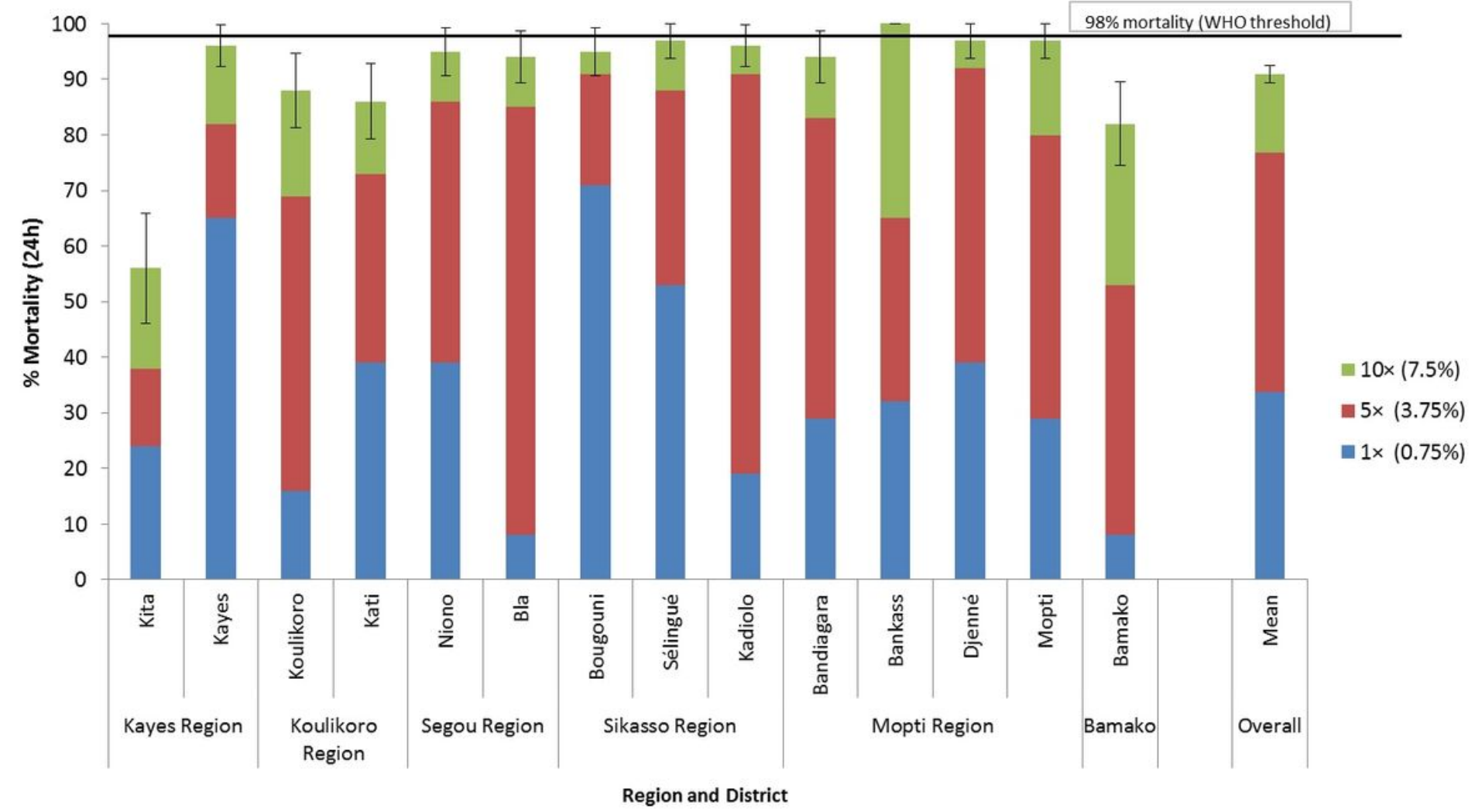


Figure 5

$\%$ Mortality of An. gambiae s.l. tested in WHO tube tests using $1 \times(0.75 \%), 5 \times(3.75 \%)$ and $10 \times(7.5 \%)$ the diagnostic concentration of permethrin in 2018.

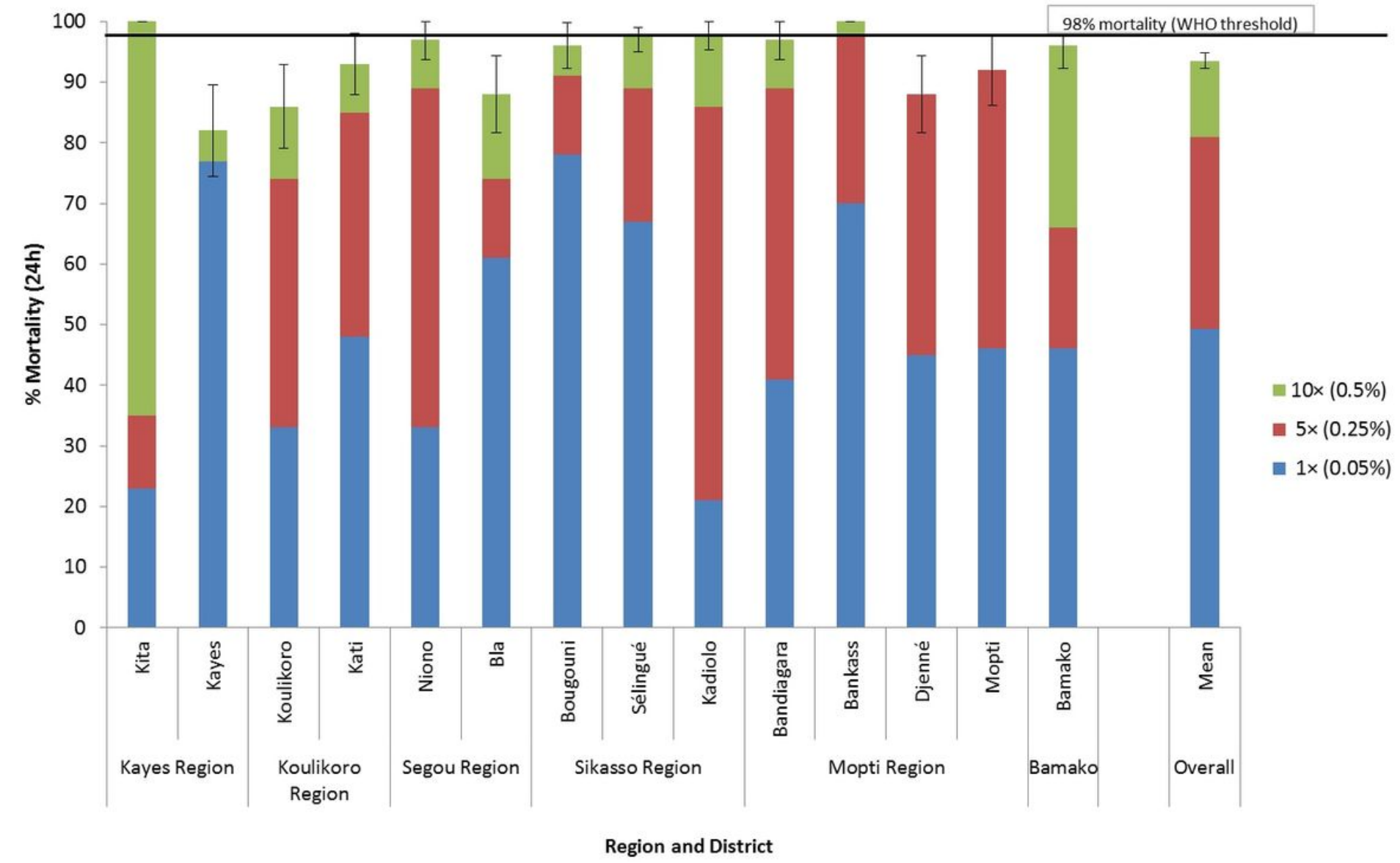

Figure 6

$\%$ Mortality of An. gambiae s.I. tested in WHO tubes using $1 \times(0.05 \%), 5 \times(0.25 \%)$ and $10 \times(0.5 \%)$ the diagnostic concentration of deltamethrinin 2018. 

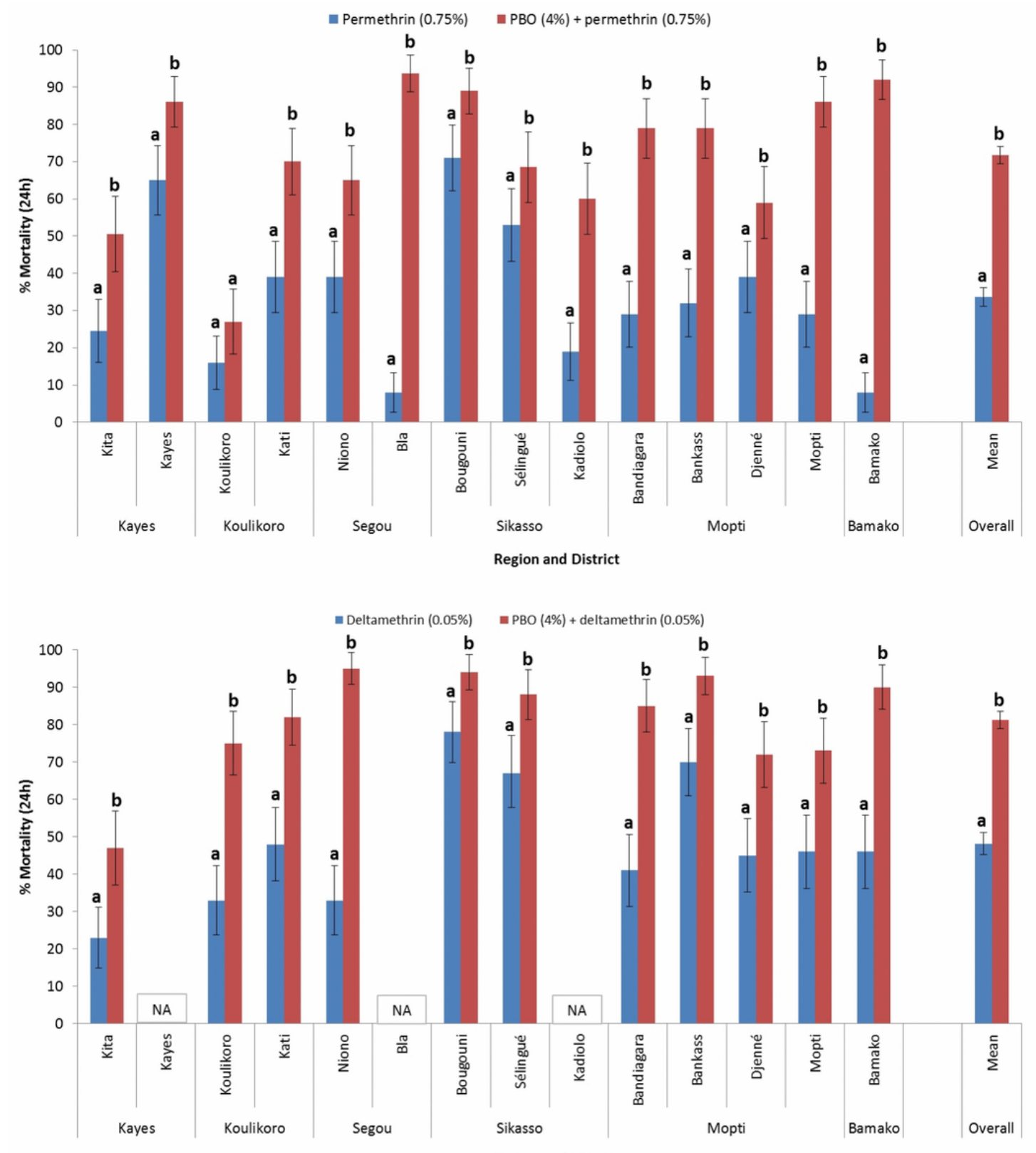

Region and District

\section{Figure 7}

Figure 7a: \% Mortality (24h) of An. gambiae s.I. tested with permethrin (0.75\%) alone and after pre-exposure to PBO (4\%) synergist using WHO tube tests (bars for the same site sharing the same letter superscript a, b do not differ significantly, $\mathrm{P}>0.05)$. Figure $7 \mathrm{~b}$ : \% Mortality (24h) of An. gambiae s.I. tested with deltamethrin (0.05\%) alone and after pre-exposure to PBO (4\%) synergist using WHO tube tests (bars for the same site sharing the same letter superscript $a$, b do not differ significantly, $P>0.05 ; N A=$ No data). 


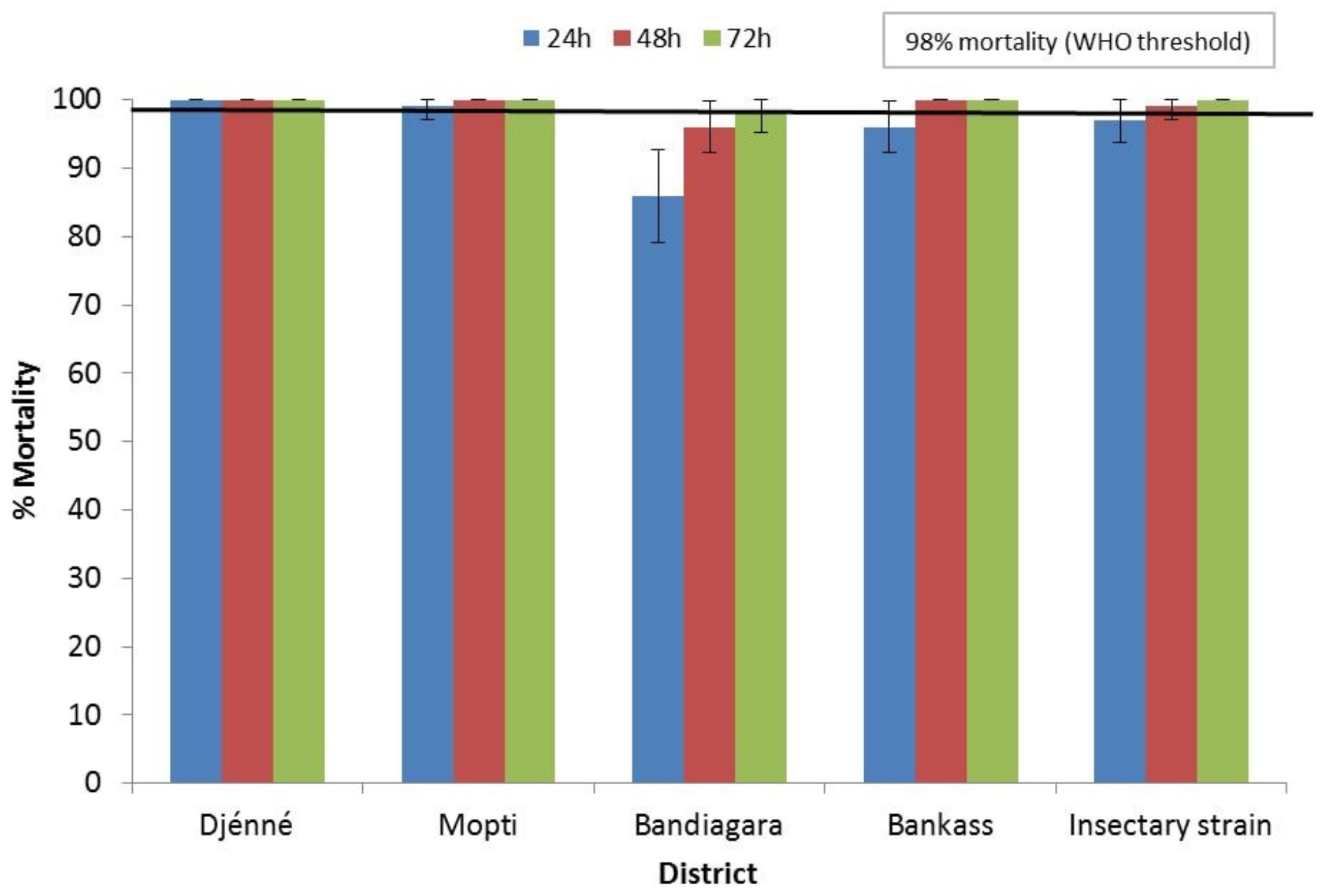

Figure 8

Results of An. gambiae s.I. (field collected as larvae) and An. coluzzii Ngousso (susceptible insectary strain) susceptibility tests against chlorfenapyr (100 $\mu \mathrm{g}$ ai/bottle) in 2017. 


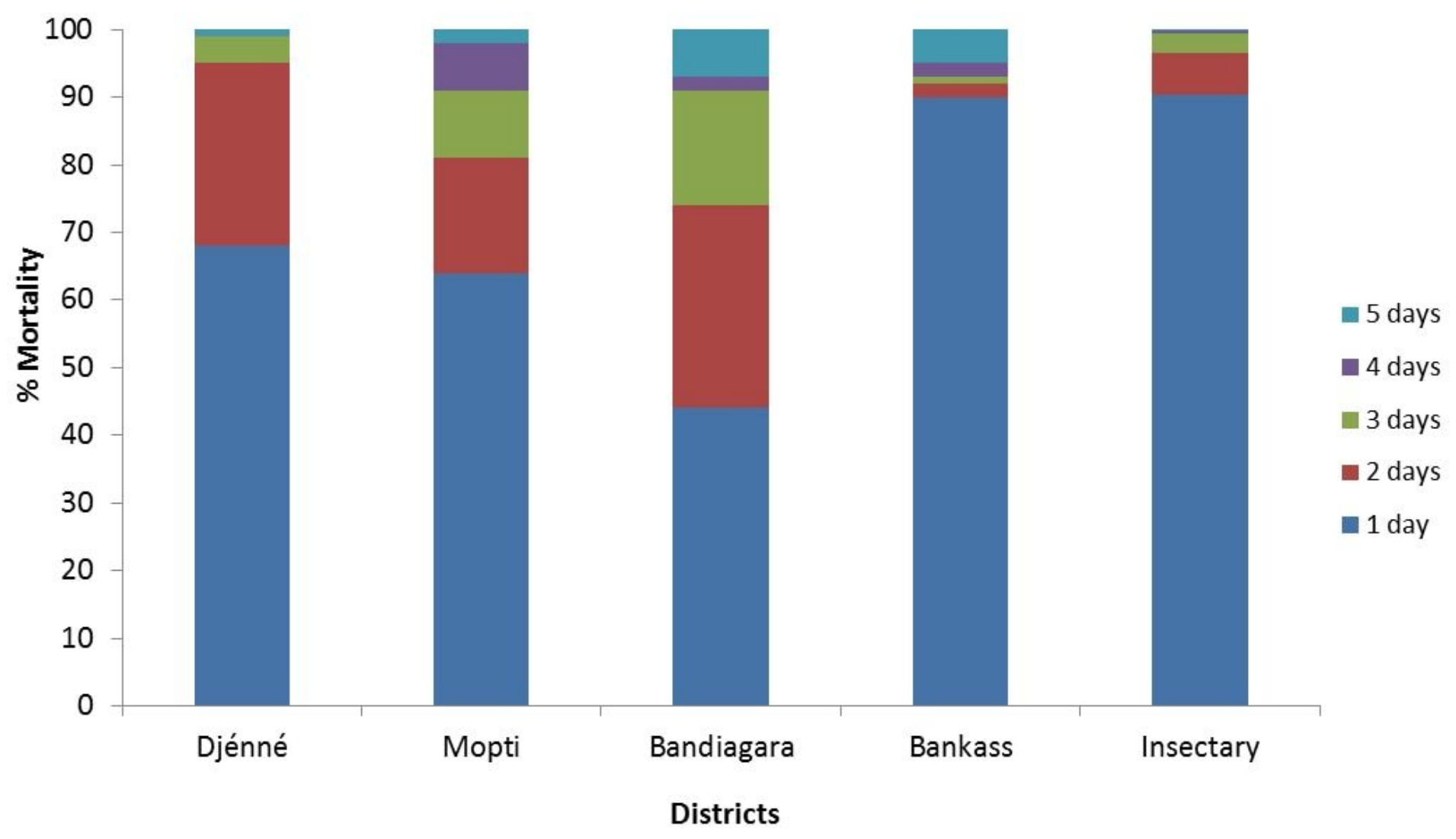

Figure 9

Mortality of An. gambiae s.I. (collected as larvae) from four IRS sites tested against clothianidin 2\% in WHO tube tests in 2018. 

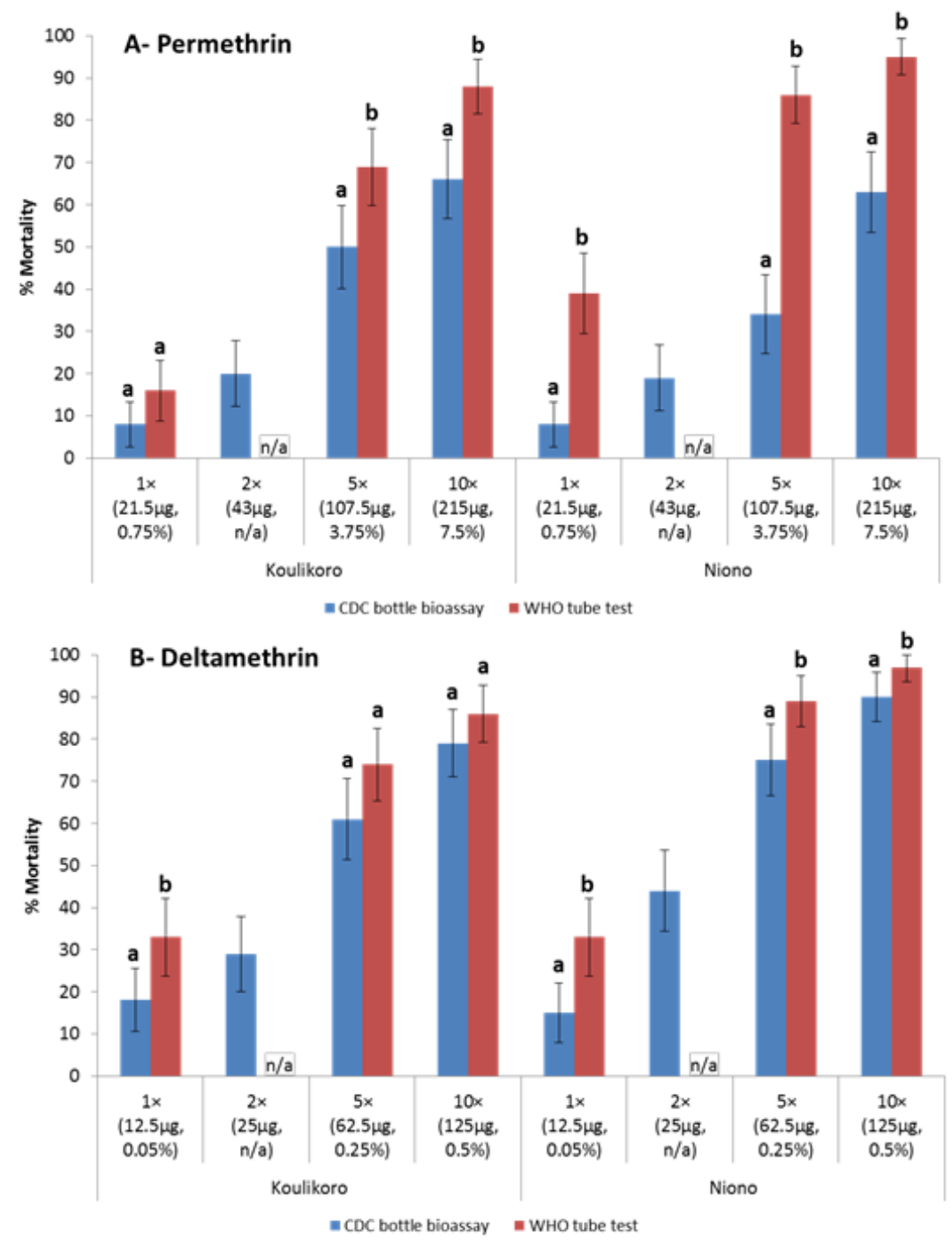

Figure 10

\% Mortality of An. gambiae s.I. in WHO tube test (24h mortality) and CDC bottle bioassay (30 mins mortality) to permethrin (A) and deltamethrin (B) in Koulikoro and Niono. Statistical comparison was made comparing the results of WHO tube tests and $C D C$ bottle bioassay by site and dose tested. Superscript of $a, a=$ no significant difference $P>0.05 ; a, b=$ significant difference $\mathrm{P}<0.05$. (n/a=no data, $2 x$ dose not tested for WHO tube test). 


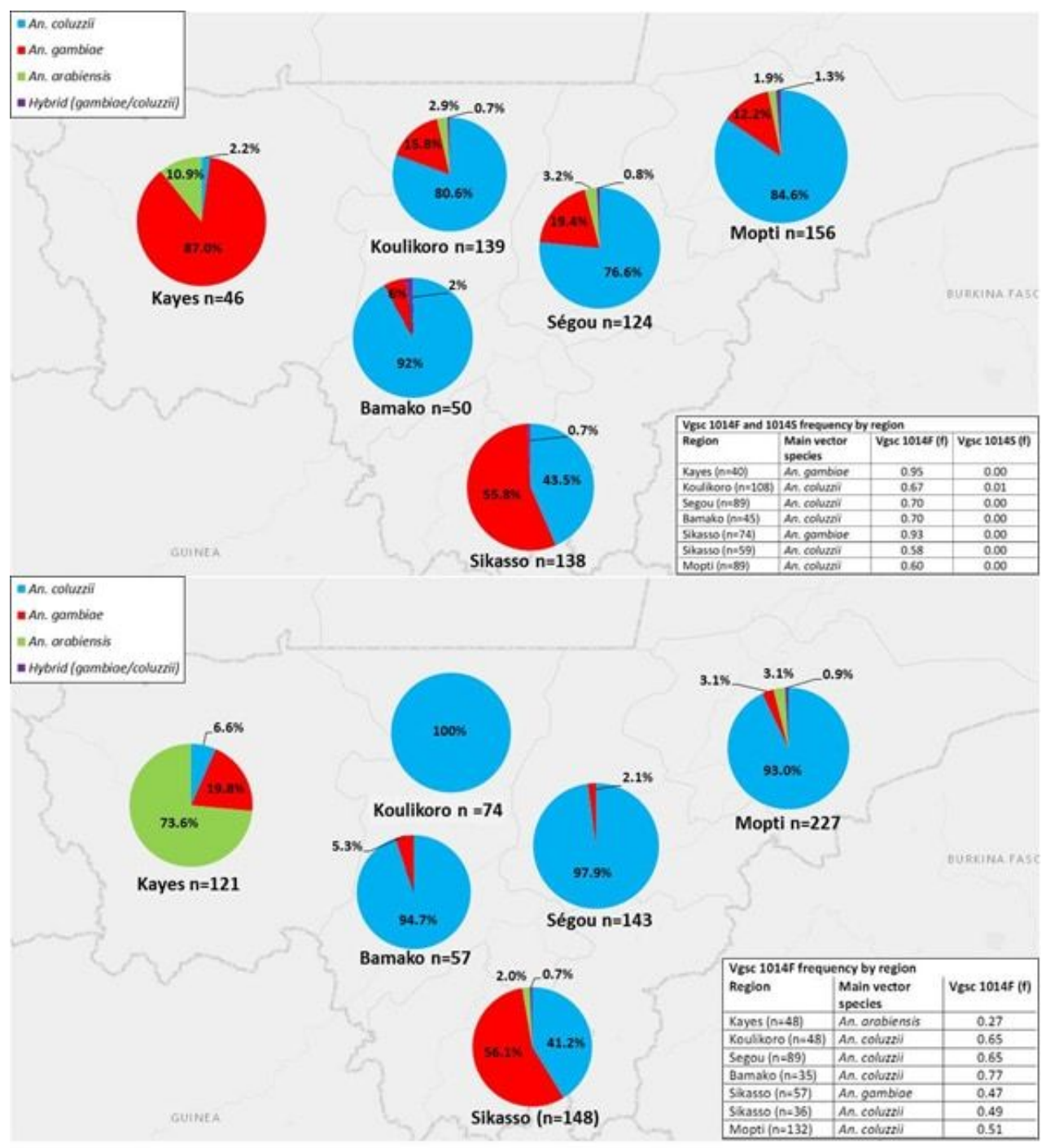

Figure 11

An. gambiae s.l. sibling species composition and vgsc 1014F and 1014S frequency in the 6 surveyed regions in 2017 (top) and 2018 (bottom). 